\title{
Perspective \\ The Effects of the Preferential 5-HT2A Agonist Psilocybin on Prepulse Inhibition of Startle in Healthy Human Volunteers Depend on Interstimulus Interval
}

\author{
Franz X Vollenweider*,', Philipp A Csomor', Bernhard Knappe', Mark A Geyer ${ }^{2}$ and Boris B Quednow' \\ 'University Hospital of Psychiatry, Neuropsychopharmacology and Brain Imaging \& Heffter Research Center, Lenggstrasse, Zürich, Switzerland; \\ ${ }^{2}$ Department of Psychiatry, University of California at San Diego, La Jolla, CA, USA
}

\begin{abstract}
Schizophrenia patients exhibit impairments in prepulse inhibition (PPI) of the startle response. Hallucinogenic 5- $\mathrm{HT}_{2 \mathrm{~A}}$ receptor agonists are used for animal models of schizophrenia because they mimic some symptoms of schizophrenia in humans and induce PPI deficits in animals. Nevertheless, one report indicates that the $5-\mathrm{HT}_{2 \mathrm{~A}}$ receptor agonist psilocybin increases PPI in healthy humans. Hence, we investigated these inconsistent results by assessing the dose-dependent effects of psilocybin on PPI in healthy humans. Sixteen subjects each received placebo or 115,215, and $315 \mu \mathrm{g} / \mathrm{kg}$ of psilocybin at 4-week intervals in a randomized and counterbalanced order. PPI at 30-, 60-, 120-, 240-, and 2000-ms interstimulus intervals (ISIs) was measured 90 and 165 min after drug intake, coinciding with the peak and post-peak effects of psilocybin. The effects of psilocybin on psychopathological core dimensions and sustained attention were assessed by the Altered States of Consciousness Rating Scale (5D-ASC) and the Frankfurt Attention Inventory (FAIR). Psilocybin dosedependently reduced PPI at short (30 ms), had no effect at medium (60 ms), and increased PPI at long (I20-2000 ms) ISIs, without affecting startle reactivity or habituation. Psilocybin dose-dependently impaired sustained attention and increased all 5D-ASC scores with exception of Auditory Alterations. Moreover, psilocybin-induced impairments in sustained attention performance were positively correlated with reduced PPI at the $30 \mathrm{~ms}$ ISI and not with the concomitant increases in PPI observed at long ISIs. These results confirm the psilocybin-induced increase in PPI at long ISIs and reveal that psilocybin also produces a decrease in PPI at short ISIs that is correlated with impaired attention and consistent with deficient PPI in schizophrenia.

Neuropsychopharmacology (2007) 32, I876-I887; doi: I0.1038/sj.npp. I 30 I324; published online I 4 February 2007
\end{abstract}

Keywords: PPI; startle; psilocybin; serotonin; 5-HT2A; 5-HTIA

\section{INTRODUCTION}

Prepulse inhibition (PPI) of the acoustic startle response (ASR) has been established as an operational measure of sensorimotor gating (Braff et al, 1978, 1992). PPI is defined as a reduction of the startle reflex that occurs when a loud startle stimulus is preceded by a weak non-startling stimulus (Graham, 1975). According to the sensorimotor gating concept, PPI is considered as an example of mechanisms that limit sensory information overflow, facilitate selective attention, and enable efficient processing of relevant information. Reductions in PPI have been demonstrated with some consistency in schizophrenia (eg, Braff et al, 1978, 1992; Ludewig et al, 2003a, b; Kumari et al,

*Correspondence: Dr FX Vollenweider, University Hospital of Psychiatry, Clinical Research \& Heffter Research Center, Lenggstrasse 31, CH-8032 Zurich, Switzerland, Tel: + 4I 4438426 04, Fax: + 4 I 4438433 96, E-mail: vollen@bli.unizh.ch

Received 18 July 2006; revised 29 October 2006; accepted 20 November 2006
2000; Parwani et al, 2000; Quednow et al, 2006), schizotypal personality disorder (Cadenhead et al, 1993, 2000), and psychotic bipolar mania (Perry et al, 2001). These results contributed to the view that schizophrenia patients suffer from a sensory inundation caused by a general inability to filter out relevant from irrelevant external stimuli automatically (Geyer and Braff, 1987).

The impaired sensorimotor gating process in schizophrenia is proposed to parallel a neurobiological abnormality in this disease (Geyer and Braff, 1987; Swerdlow et al, 2000; Swerdlow et al, 2001). To enhance our knowledge of the pathophysiology responsible for the PPI deficits in schizophrenia (and, therefore, of the disease itself) as well as to develop translational animal model studies, investigators have increasingly utilized psychopharmacological modulation of PPI in normal humans and animals (Braff et al, 2001; Geyer et al, 2001). Treatment with dopamine (DA) receptor agonists, serotonin-2A $\left(5-\mathrm{HT}_{2 \mathrm{~A}}\right)$ receptor agonists, or glutamatergic $\mathrm{N}$-methyl-D-aspartate (NMDA) antagonists, as well as developmental manipulations such as isolation rearing or neonatal lesions, causes PPI deficits in rats that 
can be abolished by pre- or post-treatment with antipsychotics (for review see Geyer et al (2001)). As a result of these findings and the fact that especially hallucinogenic 5$\mathrm{HT}_{2 \mathrm{~A}}$ agonists and NMDA antagonists mimic some features of schizophrenia in humans (Vollenweider, 1998, 2001; Vollenweider and Geyer, 2001), PPI has been proposed as an animal model for detecting antipsychotic activity (Swerdlow et al, 1994; Swerdlow and Geyer, 1998). As a consequence, it was also supposed that the PPI deficit of schizophrenia patients is linked to alterations in central serotonergic, glutamatergic, and/or dopaminergic neurotransmission (Geyer et al, 1990, 2001; Swerdlow and Geyer, 1998).

In rodents, it was shown that the $5-\mathrm{HT}_{2 \mathrm{~A}}$ receptor plays a critical role in the modulation of PPI. The hallucinogenic $5-\mathrm{HT}_{2 \mathrm{~A} / 2 \mathrm{C}}$ receptor agonist DOI consistently disrupts PPI in rats and this effect could be blocked by the selective $5-\mathrm{HT}_{2 \mathrm{~A}}$ receptor antagonist MDL 100907 (Padich et al, 1996; Sipes and Geyer, 1995) but not by the selective $5-\mathrm{HT}_{2 \mathrm{C}}$ receptor antagonist SDZ SER 082 (Sipes and Geyer, 1995). Moreover, Sipes and Geyer (1997) infused DOI directly into 5- $\mathrm{HT}_{2 \mathrm{~A}}$ receptor-rich regions such as the nucleus accumbens and the ventral pallidum of rats. They found that only infusion into the ventral pallidum decreased PPI, providing strong evidence for the importance of this region in serotonergic influences on sensorimotor gating. In contrast to these animal findings, Gouzoulis-Mayfrank et al (1998b) reported increased PPI in healthy human volunteers after administration of the hallucinogenic $5-\mathrm{HT}_{2 \mathrm{~A} / 1 \mathrm{~A}}$ agonist psilocybin. This result raised questions regarding the comparability of drug effects on PPI across species as well as the putative relevance of psilocybin-induced model psychoses to schizophrenia. However, Gouzoulis-Mayfrank et al (1998b) used psilocybin rather than DOI, a small sample size, and a crosssectional placebo-controlled design ( $n=6$ in each group). Furthermore, in their startle sequence only an interstimulus interval (ISI) of $100 \mathrm{~ms}$ was applied for the prepulse-pulse (PP) trials. Previously, it has been shown that PPI induced by PP combinations with ISIs of comparable duration, could be modulated by attention (Schell et al, 2000). Thus, attentional processes may have influenced the results of Gouzoulis-Mayfrank et al (1998b).

The aim of the present study was to further investigate the contradictory results on the effect of serotonergic hallucinogens on PPI between animals and humans. Accordingly, we measured PPI of ASR in 16 healthy volunteers each under placebo as well as under three different doses of the $5-\mathrm{HT}_{2 \mathrm{~A} / 1 \mathrm{~A}}$ agonist psilocybin. We applied a startle paradigm that consists of $\mathrm{PP}$ combinations ranging from short (30, $60 \mathrm{~ms}$ ), presumably 'pre-attentive' to long 'attentive' ISIs $(120,240$, and $2000 \mathrm{~ms})$. Owing to the previous consistent effects of hallucinogens in animals, we expected a dosedependent decrease of PPI in our human volunteers.

\section{MATERIALS AND METHODS}

This study was approved by the Ethics Committee of the University Hospital of Psychiatry, Zurich, and the use of psilocybin was authorized by the Swiss Federal Office for Public Health, Department of Pharmacology and Narcotics, Berne.

\section{Subjects}

Twenty healthy subjects were recruited through advertisement from local universities. All subjects were screened initially for startle reactions. Sixteen (nine female subjects and seven male subjects; mean age 26.4 years; range 21-32 years) of these 20 subjects showed robust startle and were included in the study, while four subjects failed to show measurable responses on $>50 \%$ of the pulse-alone (PA) trials and were excluded from participating in the study. Subjects were healthy according to medical history, clinical examination, electrocardiography, and blood analysis. Subjects were screened by the DIA-X diagnostic expert system (Wittchen and Pfister, 1997), a semi-structured psychiatric interview to exclude those with personal or family (first-degree relatives) histories of major psychiatric disorders, and standard psychometric instruments including the Freiburg Personality Inventory FPI (Fahrenberg et al, 1984), the State Trait Anxiety Inventory STAI (Spielberger et al, 1970), and the Hopkins Symptom Checklist SCL-90 (Derogatis et al, 1976). As the personality trait factors 'rigidity' and 'emotional lability' predict negative experiences under hallucinogens (Dittrich, 1994), scores two SD above the mean value of normative data in the respective subscales of the FPI (ie, openness and neuroticism) were used as exclusion criteria. No subjects were excluded using these criteria.

Some subjects had minimal prior drug experiences (once or twice, all more than 6 months prior to the study); all other subjects were drug-naïve. Specifically, six of the 16 subjects had tried cannabis, two MDMA, three a hallucinogen, and four were light smokers ( $<6$ cigarettes/day). All volunteers gave their written consent after being informed by a written and oral description of the study, the procedures involved, and the effects and possible risks of psilocybin administration.

\section{Psilocybin}

Psilocybin (4-phosphoryloxy- $N, N$-dimethyltryptamine) was obtained through the Swiss Federal Office of Public Health, Department of Pharmacology and Narcotics, Berne and prepared as capsules of 1 and $5 \mathrm{mg}$ at the Pharmacy of the Cantonal Hospital of Aarau, Switzerland. Psilocybin and lactose placebo were administered in gelatin capsules of identical appearance.

\section{Study Design}

The study was double-blind, placebo-controlled and included four experimental days. All subjects received placebo and three graded doses of psilocybin: 115,215 , and $315 \mu \mathrm{g} /$ $\mathrm{kg}$ body weight in a randomized and counterbalanced order separated by 4 week intervals. As a result of variations of PPI with menstrual cycle, women were tested in the first 5 days of their follicular phase where PPI has been shown to be most robust (Swerdlow et al, 1996). The doses of psilocybin were selected to be sufficient to assure differential psychological effects across doses (Hasler et al, 2004).

Sessions were conducted in a calm and comfortable laboratory environment. Participants were told to abstain from alcohol the day prior to each session and not to drink 
caffeine-containing beverages or to eat $2 \mathrm{~h}$ prior to each session. The four light smokers were told to maintain their usual smoking habits, but did not smoke during sessions. One hour after arriving in the research laboratory, subjects received placebo or psilocybin in capsules $(0900 \mathrm{~h})$. Startle measures were obtained 90 and $165 \mathrm{~min}$ after capsule intake, to coincide with the peak and post-peak effects of psilocybin. The FAIR task assessing attentional performance were conducted at $0,105,180$, and $360 \mathrm{~min}$ after treatment while the 5D-ASC rating was conducted at about 125 and $200 \mathrm{~min}$ after treatment. After the acute effects of psilocybin had subsided completely, subjects remained in the hospital for another $2 \mathrm{~h}$ and were monitored clinically.

\section{Startle Response Measurement}

The eye-blink component of the acoustic startle response was measured using an EMG startle system (EMG-SR-LAB, San Diego Instruments Inc., San Diego, CA). Two silver/ silver-chloride electrodes were placed below the right eye over the orbicularis oculi muscle and a ground electrode was placed behind the right ear over the mastoid. All electrode resistances were less than $5 \mathrm{k} \Omega$. A square wave calibrator established sensitivity to be $2.6 \mu \mathrm{V} /$ digital unit. The system recorded 250 samples at $1 \mathrm{kHz}$ sampling rate starting with the onset of the startle stimulus. EMG data were band-pass filtered $100-500 \mathrm{~Hz}$ by the acquisition hardware. Acoustic startle stimuli were presented through headphones (TDH-39-P, Maico, Minneapolis, MN). Subjects were seated comfortably in an armchair, instructed to relax, and told that they would hear a white noise for 2 min before the test noises began for about $18 \mathrm{~min}$. They were asked to stay awake while staring at a fixed point. Each session began with a 2-min acclimation period of $70-\mathrm{dB}$ background broadband noise that continued throughout the session. The session consisted of a total of 58 trials separated by inter-trial intervals varying between 10 and $20 \mathrm{~s}$. The trials consisted of three conditions: $115-\mathrm{dB}$ pulse-alone (PA) trials (broadband white noise) of $40 \mathrm{~ms}$ duration; PP trials, the PA preceded by a $86-\mathrm{dB}$ ( $16 \mathrm{~dB}$ above background) prepulse of $20 \mathrm{~ms}$ duration (broadband white noise), and a nonstimulus condition (NS). Five ISIs (onset-to-onset) were used for the PP trials: 30, 60, 120, 240, or $2000 \mathrm{~ms}$ (PP30, PP60, PP120, PP240, PP2000, respectively). The first and last blocks of a session consisted of six PA trials each that were used for the calculation of habituation but not of PPI. The two middle blocks (blocks 2 and 3), each consisted of five PA trials, three of each of the PP trials, and three NS trials presented in a pseudorandom order. All recordings were screened to exclude spontaneous eye-blink activity prior to data analysis, with about $5 \%$ of trials being excluded. Data were analyzed with the DOS-based software SRRED2 (San Diego Instruments Inc.), peak response amplitude-defined as the maximum response sample between 21 and $150 \mathrm{~ms}$ in the response window. Digital signals were smoothed by a rolling average routine of 10 successive data points. Response rejections were made both in case of onset-topeak latencies $>95 \mathrm{~ms}$ and baseline shifts $>34.2 \mu \mathrm{V}(>90$ digital units). Error trials were defined as trials in which no startle response was recorded because of a baseline shift (eg, due to spontaneous or voluntary blinks). Subjects with error trials and/or response rejections $>50 \%$ were excluded from data analysis. None the 16 subjects participating in the study had to be excluded from data analysis based on this criterion. As detailed elsewhere (Ludewig et al, 2003a), the startle measures examined were: (1) startle reactivity, the magnitude of responses on PA trials from block 1-4; (2) $\%$ habituation, according to the formula (1-(startle magnitude for PA block 1/startle magnitude for PA block 4) $\times 100$; and (3) \%PPI, according to the formula (1-(mean startle magnitude on PP trials/mean startle magnitude on PA trials $\times 100)$.

\section{The Altered State of Consciousness Rating Scale}

The Altered State of Consciousness (5D-ASC) Rating Scale (Dittrich et al, 1985; Dittrich, 1998) was used to assess the subjective effects under placebo and psilocybin. The scale is sensitive to the psychological effects of psilocybin in humans (Vollenweider et al, 1998). The 5D-ASC questionnaire is a visual-analogue scale consisting of 94 items assessing five key dimensions of altered states of consciousness (ASC), independent of their etiology (Dittrich et al, 1985; Dittrich, 1998). The 5D-ASC questionnaire consists of five scales comprising several item clusters. (1) Oceanic Boundlessness (OB), measures derealization and depersonalization accompanied by changes in affect ranging from heightened mood to euphoria and/or exaltation, and alterations in the sense of time. The corresponding item clusters are positive derealization, positive depersonalization, altered sense of time, positive mood, and mania-like experience. (2) Anxious Ego Dissolution (AED) measures ego-disintegration associated with loss of self-control, thought disorder, arousal, and anxiety. The item clusters are anxious derealization, thought disorder, delusion, fear of loss of thought control, and fear of loss of body control. (3) Visionary Restructuralization (VR) includes the item clusters elementary hallucinations, visual (pseudo-) hallucinations, synesthesia, changed meaning of percepts, facilitated recollection, and facilitated imagination. (4) Auditory Alterations (AA) comprises auditory illusions and auditory (pseudo-) hallucinations. (5) Reduction of Vigilance (RV) assesses changes in vigilance, alertness, and cognitive performance. The results of the 5D-ASC data are given as percentage scores of maximum absolute scale values.

\section{Frankfurt Attention Inventory}

Dose-dependent effects of psilocybin on sustained attention were assessed using the Frankfurt Attention Inventory (FAIR) (Moosbrugger and Oehlschlägel, 1996; Neubauer and Knorr, 2006). This paper-pencil test consists of 640 items (two sheets with 320 items) with four kinds of similar stimuli: a square with two points, a square with three points, a circle with two points or a circle with three points. Each sheet consists of 16 rows with 20 items. Within $6 \mathrm{~min}$, the participants have to select as much as possible of two target configurations (circles with three points and squares with two points) from the left side to the right side of each row. The FAIR test yields four performance measures: (1) an efficiency score (FAIR-E) providing information as to whether the participant has performed the test according 


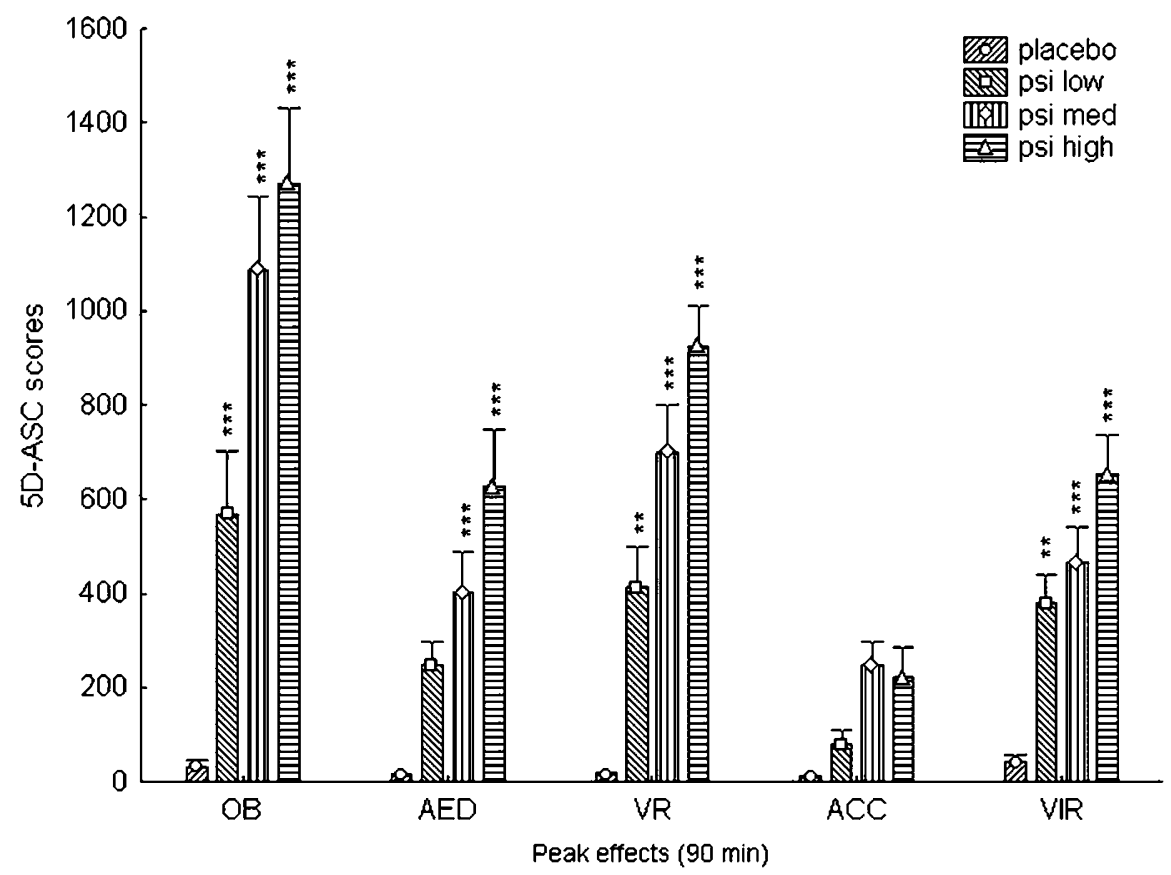

Figure I Dose-response effects of psilocybin $(1 / 5,215,315 \mu \mathrm{g} / \mathrm{kg})$ compared to placebo on the 5D-ASC obtained during the psychological peak phases of the drug. Mean scores $\pm \mathrm{SE}(n=16): \mathrm{OB}=$ oceanic boundlessness, $\mathrm{AED}=$ anxious ego dissolution, $\mathrm{VR}=$ visionary restructuralization, $\mathrm{AA}=$ auditory alterations, $\mathrm{RV}=$ reduction of vigilance. Significant changes are indicted by $* * * p_{\text {post hoc }}<0.01$; $* * * *=p_{\text {post hoc }}<0.001$.

to the instructions; (2) a score for total performance capacity (FAIR-P), which informs about the total number of items processed with attention during the test period; (3) a score for performance quality (FAIR-Q) reflecting the percentage of correctly solved items; and (4) a score for continuity of performance (FAIR-C), which is an indicator of the degree of continuously maintained attention. The FAIR task provides excellent test-retest reliability scores between 0.85 and 0.91 (Cronbach's alpha) (Moosbrugger and Oehlschlägel, 1996).

\section{Statistical Analysis}

All data were analyzed using STATISTICA 7.1 for Windows (StatSoft Inc., 2005). Startle and PPI data were analyzed using three-way analyses of variance (ANOVA) with treatment (placebo and three psilocybin doses), and session (1 and 2) as well as either test block (startle: PA block 1-4) or PP trial type (PP30, PP60, PP120, PP240, and PP2000) as within-subject factors. Subsequently separate two-way ANOVAs with treatment and PP trial type as within-subject factors were calculated for each PPI session. Two-way ANOVAs with treatment (placebo and psilocybin doses) and session (1-4) were used to test for significant effects of psilocybin on the FAIR attentional task indices, while a three-way ANOVA with 5D-ASC dimensions (OB, AED, VR, AC, VIR), treatment (placebo and three psilocybin doses), and session (1-2) as repeated measure factors, and subsequently separate two-way ANOVAs with 5D-ASC dimensions and treatment as within subject factors were used to examine the effect on the 5D-ASC scale. Based on significant main effects or interactions, Tukey's post hoc comparisons were performed. Pearson's product moment correlations were conducted to explore the relationship between \% PPI and psychological scores. The criterion for significance was set at $p<0.05$.

\section{RESULTS}

\section{Psychological Effects of Psilocybin}

As previously reported (Hasler et al, 2004; Vollenweider et al, 1997), psilocybin $(115,215,315 \mu / \mathrm{kg})$ produced an altered state that was characterized by derealization and depersonalization phenomena, affective changes, thought disorder, and perceptual alterations. The subjective effects of psilocybin began $20-40 \mathrm{~min}$ after drug intake, peaked at 60-90 min, and lasted for 1-2 h. The effects of psilocybin then gradually subsided and were completely absent $6 \mathrm{~h}$ after drug intake. During the onset of the pharmacological action of psilocybin, vegetative side effects including transient nervousness, nausea, vertigo, and somnolence were reported occasionally. The psilocybin dose regimen applied in our study was physically and mentally well tolerated by all subjects, with none of our subjects reporting persisting residual psychotropic effects in systematic followup investigations obtained 1, 3, or 90 days after completing the study.

The subjective effects of psilocybin on the 5D-ASC rating scale obtained shortly after the first and second PPI recordings are summarized in Figures 1 and 2. In concert with previous work (Hasler et al, 2004), an initial three-way ANOVA with session, drug, and 5D-ASC dimension as repeated measures revealed that the effects of psilocybin were most pronounced during the first assessment, the peak effect of the drug (interaction session $\times$ drug $\times 5 \mathrm{D}$-ASC dimension $(\mathrm{F}(12,180)=4.2, p<0.00008)$. Subsequently, two separate two-way ANOVAs with drug and 5D-ASC dimen- 


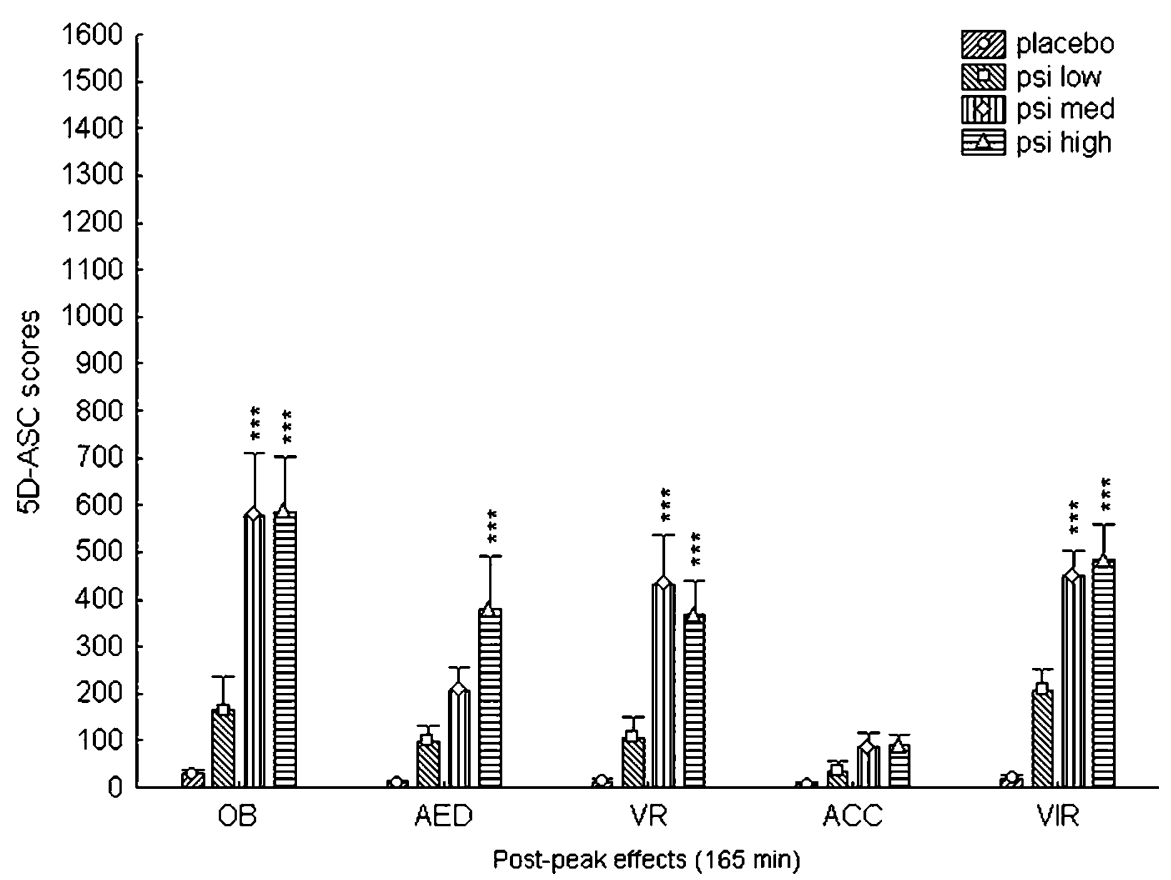

Figure 2 Dose-response effects of psilocybin $(115,215,315 \mu \mathrm{g} / \mathrm{kg})$ compared to placebo on the 5D-ASC obtained during the psychological post-peak phases of the drug. Mean scores $\pm \mathrm{SE}(n=16)$ : $O B=$ oceanic boundlessness, $A E d=$ anxious ego dissolution, $V R=$ visionary restructuralization, $\mathrm{AA}=$ auditory alterations, $\mathrm{RV}=$ reduction of vigilance. Significant changes are indicted by $* * * * p_{\text {post }}$ hoc $<0.00 \mathrm{I}$.

sions as within-subject factors were calculated for the peak and post-peak phase of the experiment. This analysis showed that during the peak effect of the drug, psilocybin significantly increased most of the 5D-ASC scores in a dose-dependent manner: trend for main effect of drug $(\mathrm{F}(3,45)=2.50 ; p<0.07)$; main effect of 5D-ASC dimensions $(\mathrm{F}(4,60)=45.9 ; \quad p<0.000001) ; \quad$ and interaction drug $\times$ 5D-ASC dimension $(\mathrm{F}(12,180)=5.74 ; p<0.000001)$. Post hoc test of the drug $\times 5 \mathrm{D}$-ASC dimension interaction showed that the increases in $\mathrm{OB}$ (effect sizes $\mathrm{d}$ ranged from 0.76 to 1.76 across doses), AED $(d=0.61-1.61)$, VR $(d=0.86-1.97)$, and RV ( $d=1.01-1.83)$ were significant (Figure 1). Further subscale scores analysis revealed that the psilocybin-induced elevation in OB scores was due mainly to increases in positively experienced depersonalization and derealization associated with heightened mood, euphoria, and with increasing dose also mania-like symptoms. The increase in AED scores was due mostly to moderate anxious ego-disintegration, thought disorder, and fear of losing control. Thought disturbances included acceleration or deceleration of thinking, thought blocking, alogia, and loosening of associations. Profound anxiety or panic did not occur in our protective experimental setting, although with the high dose of psilocybin some subjects experienced short lasting and transient episodes of paranoid thinking, altered meaning of percepts, and misinterpretation of the experimental situation. The increase in the VR score was attributable primarily to visual illusions and at high doses to visual hallucinations and synesthesia. Auditory Alterations (AA) mainly included acoustic illusions, hearing sound or melodies as well as unstructured achoasms, but none of the subjects reported hearing voices.

As shown by the aforementioned three-way ANOVA, the effect of psilocybin had already declined markedly during the second assessment, the post-peak phase. The 2-way ANOVA on the post-peak data yielded a significant main effect of drug $(\mathrm{F}(3,45)=17.2 ; p<0.00001)$; main effect of ASC dimensions $(\mathrm{F}(4,60)=13.4 ; p<0.00001)$; and interaction drug $\times$ ASC dimension $(\mathrm{F}(12,180)=5.5 ; p<0.00001)$ (Figure 2). Post hoc test of the drug $\times$ ASC dimension interaction revealed that both the medium and high dose of psilocybin significantly increased the $\mathrm{OB}(d=1.24$ and 1.26 , respectively), AED ( $d=0.69$ and 1.28$)$, VR $(d=1.32$ and $1.11)$, and RV ( $d=1.54$ and 1.66) scores (although to a much lesser extent compared to the peak phase).

\section{Attentional Performance}

As shown in Figure 3, psilocybin impaired attentional performance on the FAIR task in dose-dependent manner. Specifically, psilocybin significantly reduced the FAIR attentional performance capacity score $P$ (interaction drug $\times$ session: $F(9,135)=10.3, p<0.00001)$ and the FAIR score $Q$ indexing the amount of attentively made decisions relative to the total decisions (interaction drug $\times$ session: $\mathrm{F}(9,135)=2.69, p<0.006)$ as well as the attentional continuity performance score $C$ (interaction drug $\times$ session: $\mathrm{F}(9,135)=5.22, p<0.00001)$. Post hoc testing revealed that the reduction in $P$ and $C$ scores was significant after low (effect sizes in the peak: $d=1.03$ and 0.86 , respectively), medium $(d=1.27$ and 1.13), or high dose $(d=1.17$ and 1.13) of psilocybin and during both the peak and post-peak effect of psilocybin, while the reduction in the $Q$ score was significant only after high dose psilocybin and during the peak effect of the drug $(d=0.95)$. Psilocybin did not significantly affect the efficiency score $E$ assessing the comprehension of the task. 


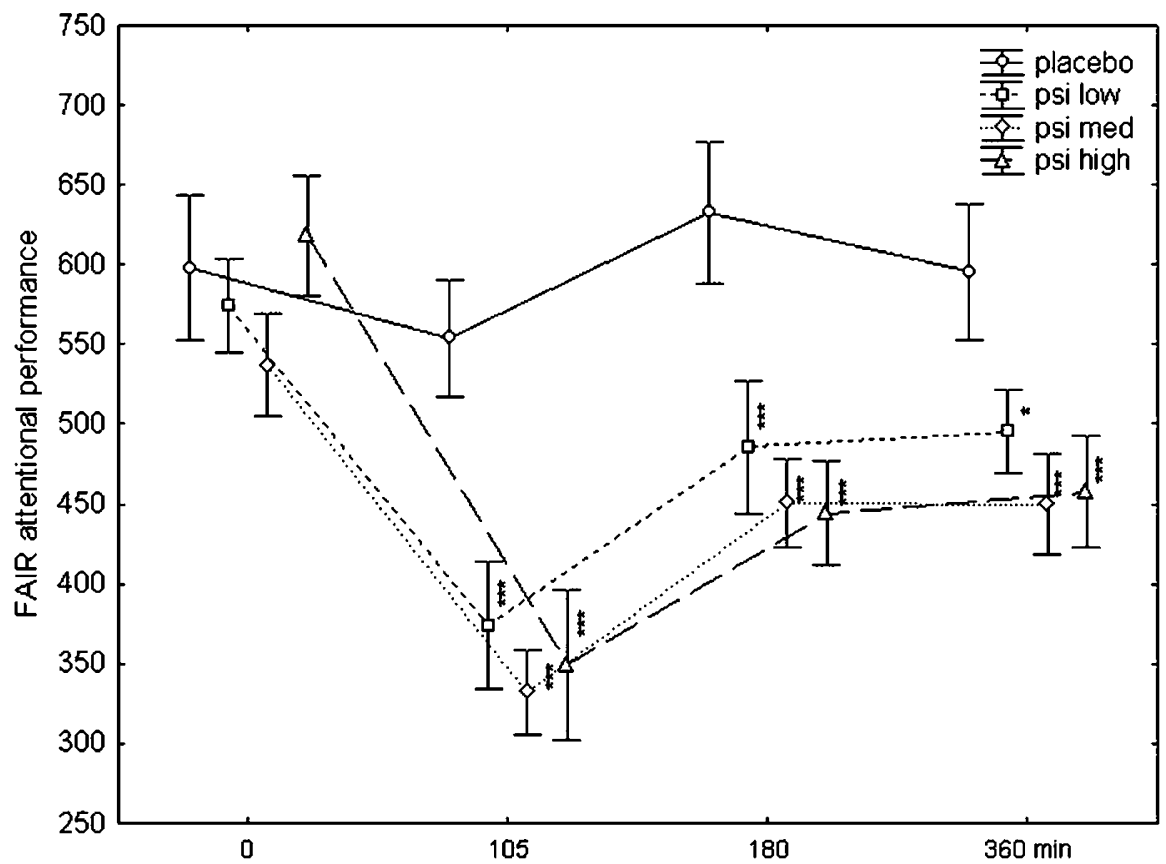

Figure 3 Dose-response effects of psilocybin $(115,215,315 \mu \mathrm{g} / \mathrm{kg})$ compared to placebo on the FAIR attentional performance score $P$ in healthy human volunteers obtained at 0, 105 (during the peak phase), I 80 and 360 min after drug intake $(n=16)$. Significant differences are indicated by $*=p_{p o s t}$ hoc $<0.05$; ***** $=$ p post hoc $<0.001$.

Table I Mean Startle Amplitudes of Block 2 and 3 during Placebo and Psilocybin Conditions

\begin{tabular}{|c|c|c|c|c|c|c|c|c|}
\hline & \multicolumn{2}{|c|}{ Placebo } & \multicolumn{2}{|c|}{ Low-dose psi } & \multicolumn{2}{|c|}{ Medium-dose psi } & \multicolumn{2}{|c|}{ High-dose psi } \\
\hline & Mean & SE & Mean & SE & Mean & SE & Mean & SE \\
\hline Session 2 & 281.0 & 37.3 & $3 \mid 4.8$ & 43.4 & 273.1 & 35.1 & 301.0 & 50.8 \\
\hline
\end{tabular}

\section{Effect of Psilocybin on Startle Amplitude and Habituation}

As shown in Table 1, none of the psilocybin doses used significantly affected startle reactivity during the psychological peak or post-peak phases compared to placebo. There was a significant session $\times$ block interaction $(\mathrm{F}(3,45)=2.88$, $p<0.045)$, indicating that startle reactivity pooled over doses may differ in a given block between sessions. However, post hoc testing revealed no significant pairwise differences. Subsequent collapsing of the data over dose and session revealed a significant main effect of block $(\mathrm{F}(3,45)=138.4, p<0.00001)$ with lower startle reactivity in the later than in earlier blocks, reflecting the phenomenon of habituation. However, the lack of a significant drug $x$ block interaction indicates that psilocybin did not affect habituation. An additional analysis of the \%habituation data confirmed that habituation was not altered after psilocybin at any dose.

\section{Effect of Psilocybin on Percent PPI}

The effects of psilocybin on \%PPI are summarized in Figures 4 and 5. An initial three-way ANOVA indicated that psilocybin has similar overall effects on PPI across the different PPI conditions during both the psychological peak and post-peak phases of the drug effect. Specifically, psilocybin appears to reduce PPI at short, have no effect at medium, and increase PPI at long ISIs (drug $\times$ PP-condition interaction: $\mathrm{F}(12,180)=4.97, p<0.000001)$. Furthermore, inspection of the data and the significant session $\times$ drug interaction $(F(3,45)=3.76, p<0.01)$ indicated that these effects differ across sessions and were more pronounced during the first than the second assessment.

Given this observation and the fact that the psychological effects of psilocybin had already substantially subsided during the second PPI session, separate two-way ANOVAs were subsequently conducted for the first and second PPI assessment. This analysis again showed that psilocybin had either no or opposite effects on \%PPI at short and long PP intervals (drug $\times$ PP-condition interaction: $\mathrm{F}(12,180)=5.75$, $p<0.000001$ ) (Figure 4). Post hoc testing confirmed that the reduction in \%PPI was significant at the $30 \mathrm{~ms}$ PP interval for the low (effect size $d=0.80)$, medium $(d=0.83$ ), and high doses $(d=0.71)$ of psilocybin, and that the increase in $\%$ PPI was significant at the $120 \mathrm{~ms}$ interval for the medium dose $(d=0.63)$, at the $240 \mathrm{~ms}$ interval for the low $(d=0.40)$, medium $(d=0.90)$, and high doses $(d=0.61)$, and at the 


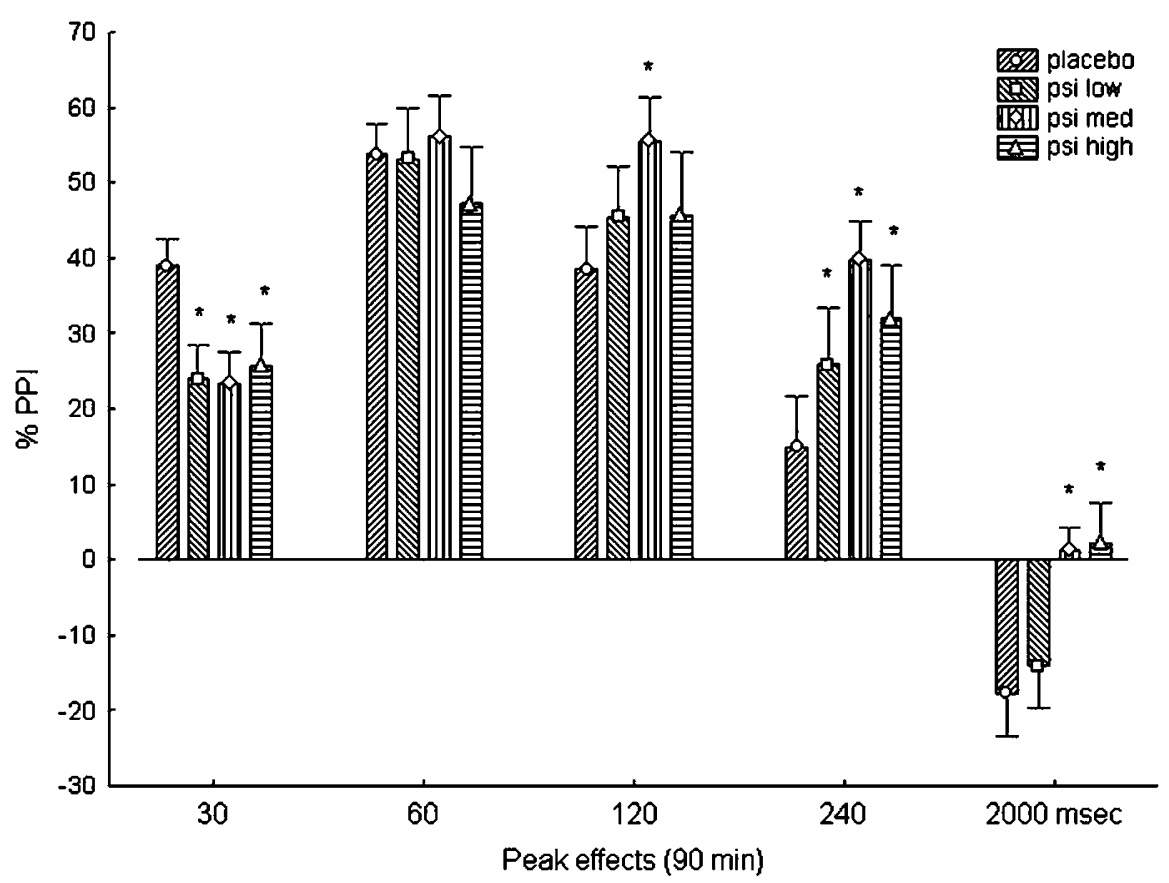

Figure 4 Dose-response effects of psilocybin (II5, 215,315 $\mu \mathrm{g} / \mathrm{kg})$ compared to placebo on percentage prepulse inhibition (\%; mean \pm SE) at five PP conditions (ISI: 30, 60, 120, 240, and $2000 \mathrm{ms)}$ in healthy human volunteers obtained during the psychological peak phases of the drug ( $n=16$ ). $|S|=$ interstimulus-interval. Significant differences are indicated by ${ }^{*}=p_{\text {post hoc }}<0.05$.

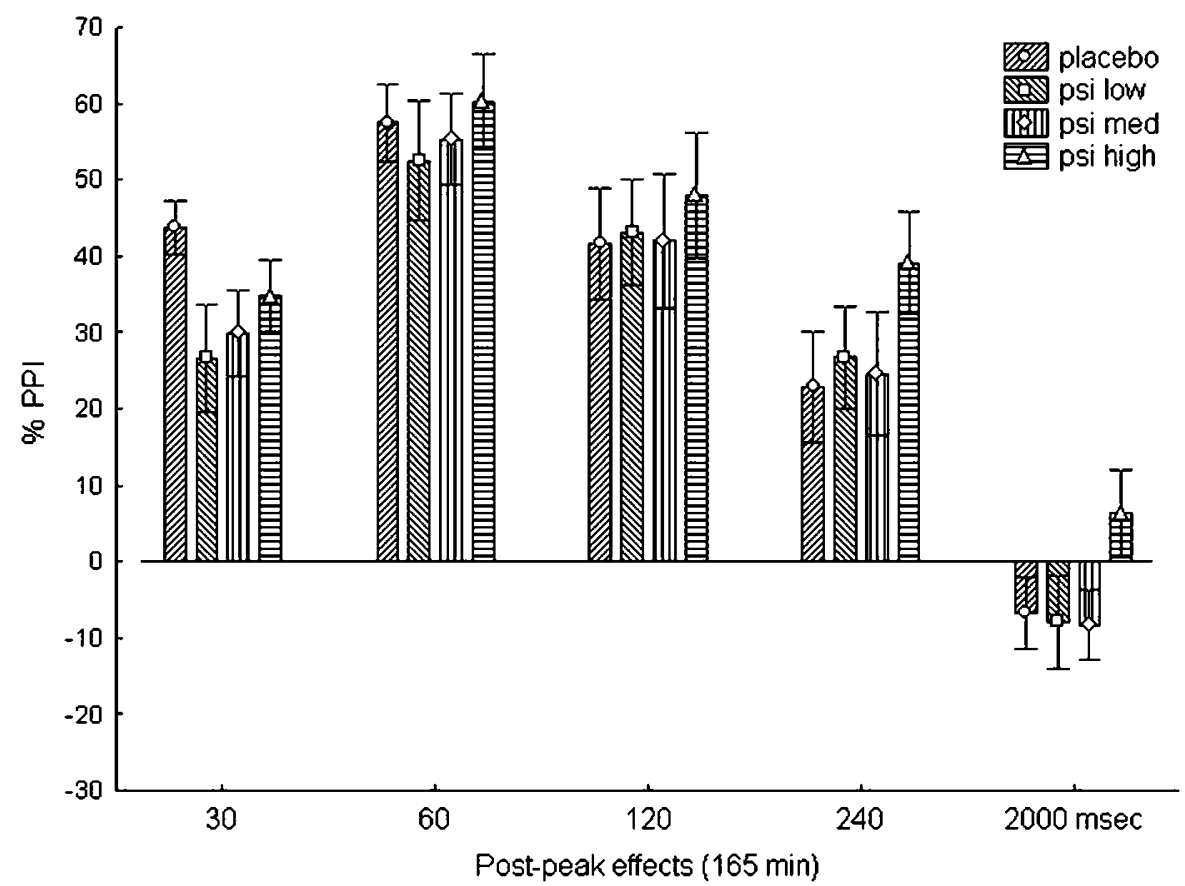

Figure 5 Dose-response effects of psilocybin on percentage prepulse inhibition (\%; mean \pm SE) at five PP conditions (ISI: 30, 60, I20, 240, and 2000 ms) in healthy human volunteers during the psychological post-peak phases of the drug $(n=\mid 6)$. ISI = interstimulus-interval.

$2000 \mathrm{~ms}$ interval for the medium $(d=0.88)$ and high doses $(d=0.92)$. A similar analysis and post hoc testing of the PPI data of the post-peak phase revealed only a weak trend towards a drug $\times \mathrm{PP}$-condition interaction $(\mathrm{F}(12,180)=1.5$, $p=0.12$, reflecting that the highest dose of psilocybin still reduced \%PPI somewhat at the $30 \mathrm{~ms}$ and increased PPI at the 240 and $2000 \mathrm{~ms}$ lead intervals (Figure 5).

\section{Relationships of PPI and Clinical Symptoms}

To explore the relationship between PPI and clinical symptoms in psilocybin states, data obtained during the peak effects of psilocybin were pooled across doses $(n=48)$ and correlation analyses between PPI and the FAIR or the 5D-ASC scale scores were performed. This analysis revealed 


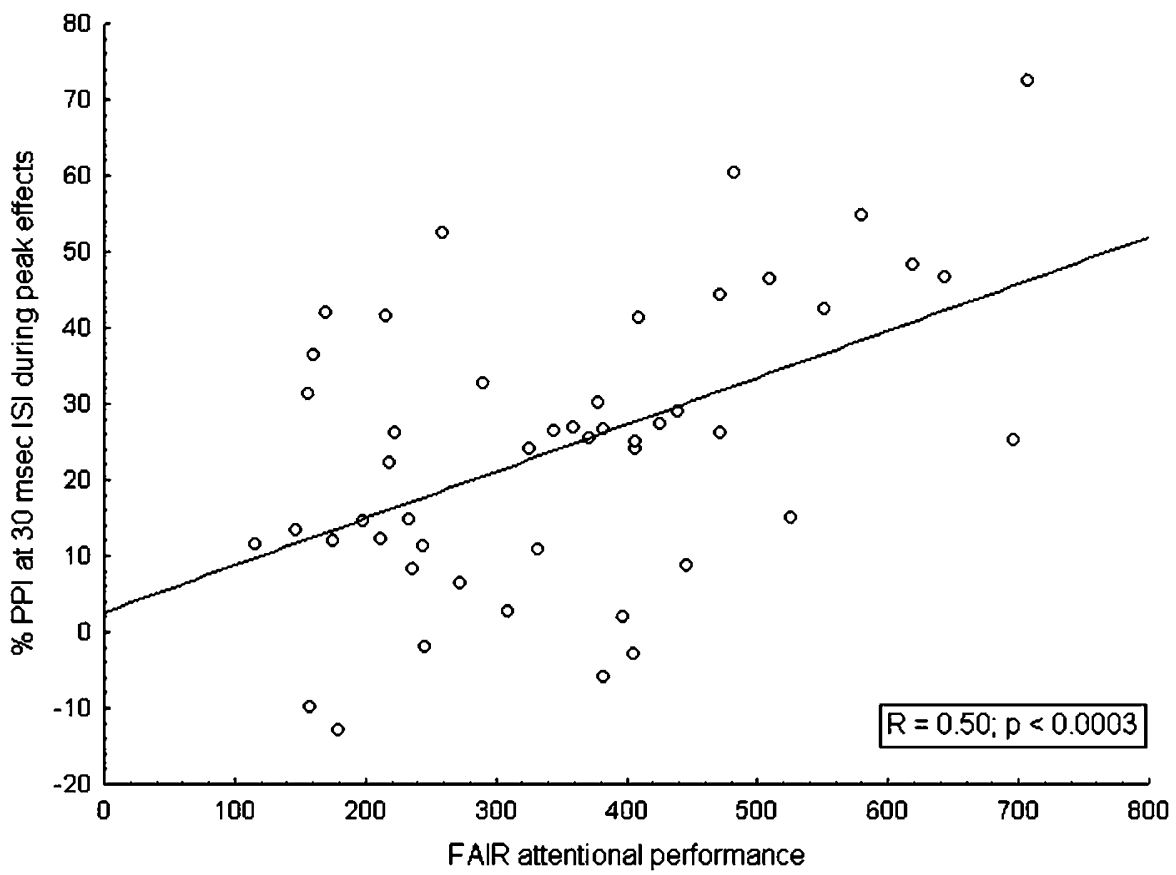

Figure 6 Correlation between FAIR attentional performance ( $P$ scores) and percentage prepulse inhibition (\%PPI) of pooled data across psilocybin doses obtained at the $30 \mathrm{~ms}$ lead interval during the psychological peak phases of the drug $(n=48) . R=0.49, p<0.0004$.

that the \%PPI obtained at the $30 \mathrm{~ms}$ lead interval correlated significantly with attentional performance $(P$ score $)$ on the FAIR task $(R=0.50, p<0.0003)$ (Figure 6). A similar correlation was found for the attentional continuity score $C$ $(R=0.49, p<0.0004)$. There were no other significant correlations between PPI performance and the FAIR or any of the 5D-ACS scores (range of $R$ from -0.06 to 0.18 ).

\section{DISCUSSION}

This dose-response study with the mixed $5-\mathrm{HT}_{2 \mathrm{~A} / 1 \mathrm{~A}}$ though preferential $5-\mathrm{HT}_{2 \mathrm{~A}}$ agonist psilocybin in humans was undertaken to clarify the disparity between previous reports of PPI-increasing effects of psilocybin in humans (Gouzoulis-Mayfrank et al, 1998b) and PPI-disrupting effects of serotonergic hallucinogens in animals (Sipes and Geyer, 1995; Geyer, 1998). The present study yielded three main results. First, psilocybin reduced PPI at short $(30 \mathrm{~ms})$, had no effect at medium $(60 \mathrm{~ms})$, and increased PPI at long (120-2000 ms) ISIs in a dose-dependent manner, while startle reactivity and habituation remained unaffected. Second, concomitantly psilocybin elicited an altered state of consciousness characterized by derealization and depersonalization phenomena, thought disorder, affective changes, and visual disturbances including positive and negative symptoms of schizophrenia (Gouzoulis-Mayfrank et al, 1998a; Vollenweider and Geyer, 2001). Third, psilocybin impaired sustained attention, a finding that was positively correlated with the psilocybin-induced reductions in PPI at the shortest and presumably preattentive ISI condition and not with the increases in PPI at longer ISIs. Taken together, the present findings indicate that activation of $5-\mathrm{HT}_{2 \mathrm{~A}}$ and/or $5-\mathrm{HT}_{1 \mathrm{~A}}$ receptors can disrupt PPI of acoustic startle in humans and provide further evidence that disrupted gating may lead to cognitive disturbances (McGhie and Chapman, 1961; Braff et al, 1992).

The present finding that psilocybin increased PPI at longer ISIs (120-2000 ms) confirms previous work demonstrating that a dose of psilocybin $(200 \mu \mathrm{g} / \mathrm{kg})$ - comparable to the medium dose used in the present study - produced a mild although significant increase in PPI at a prepulseto-pulse (PP) interval of $100 \mathrm{~ms}$ in healthy volunteers (Gouzoulis-Mayfrank et al, 1998b). In both studies, psilocybin had no significant effect on startle reactivity or habituation. Moreover, the PPI-enhancing effect seen in the present study at longer ISIs was dose-dependent and thus did not confirm our hypothesis that higher doses of psilocybin $(215$ and $315 \mu \mathrm{g} / \mathrm{kg})$ than that used in the study of Gouzoulis and co-workers $(200 \mu \mathrm{g} / \mathrm{kg})$ would lead to a disruption of PPI. In contrast, a recent study of effects of the DMT-containing hallucinogenic beverage ayahuasca in healthy volunteers found no significant effect on PPI using prepulse intervals of $60,120,240$, and $2000 \mathrm{~ms}$ (Riba et al, 2002). A possible explanation that ayahuasca DMT failed to affect PPI in humans may be due to the fact that DMT is a very short acting hallucinogenic $5-\mathrm{HT}_{2 \mathrm{~A} / 1 \mathrm{~A}}$ agonist (approximately $1-3 \mathrm{~h}$ ) and that the effects on the 5D-ASC dimensions in the study of Riba and co-workers were considerably smaller than those seen in the present study with psilocybin. However, the PPI-enhancing effect seen with increasing doses of psilocybin in humans at long ISIs contrasts with a number of animal studies reporting that specific $5-\mathrm{HT}_{2 \mathrm{~A} / 2 \mathrm{C}}$ agonists such as DOI or mescaline disrupt PPI in rats (Padich et al, 1996; Sipes and Geyer, 1994, 1995, 1997). Specifically, it was found that DOI dosedependently disrupts PPI at ISIs of $100 \mathrm{~ms}$ without significantly affecting startle reactivity (Sipes and Geyer, 1995). Moreover, it was found that the PPI-disrupting effect 
of DOI was blocked by the highly specific $5-\mathrm{HT}_{2 \mathrm{~A}}$ antagonist $\mathrm{M} 100,907$, but not by $5-\mathrm{HT}_{2 \mathrm{C}}$ antagonists, suggesting that the disruption of PPI in the rat is mediated by $5-\mathrm{HT}_{2 \mathrm{~A}}$ rather than $5-\mathrm{HT}_{2 \mathrm{C}}$ receptors (Sipes and Geyer, 1995, 1997).

Nevertheless, the present findings not only confirm previous work that psilocybin enhances PPI at long prepulse intervals in humans (Gouzoulis-Mayfrank et al, 1998b), but also demonstrate that psilocybin disrupts PPI at short prepulse intervals of $30 \mathrm{~ms}$. Given that we found no correlations between the psilocybin-induced increases in PPI at long ISIs and any of the attentional or states of consciousness scores, we can only conclude that the physiological significance of these increases in PPI are related to unknown processes that were not assessed in the present study. As psilocybin had no effect on startle reactivity, it appears that psilocybin targets startle circuits that are involved in inhibitory processes rather than having a generalized effect on startle reactivity. Similarly, no effect on startle reactivity was found after administration of a comparable dose of psilocybin $(200 \mu \mathrm{g} / \mathrm{kg})$ in rats (Davis and Walters, 1977). The finding that psilocybin did not significantly affect startle amplitude and habituation of the ASR in the present study is also consistent with animal studies demonstrating that comparable doses of the $5-\mathrm{HT}_{2 \mathrm{~A} / 2 \mathrm{C}}$ agonist DOI $(0.25$ and $0.5 \mathrm{mg} / \mathrm{kg})$ did not alter startle in rats (Sipes and Geyer, 1995, 1997). In addition, direct infusion of DOI $(1.0-10.0 \mu \mathrm{g} / 0.5 \mu \mathrm{l})$ into the ventral pallidum or the nucleus accumbens, which are important in the modulation of PPI, also did not change startle reactivity (Sipes and Geyer, 1997). Only high doses of the $5-\mathrm{HT}_{2 \mathrm{~A} / 2 \mathrm{C}}$ agonists DOI $(>2 \mathrm{mg} / \mathrm{kg})$ and DOB $(3 \mu \mathrm{mol} / \mathrm{kg})$ reduced startle amplitude in rats (Johansson et al, 1995; Padich et al, 1996).

The PPI-disrupting effect of psilocybin at the short ISI of $30 \mathrm{~ms}$ is consistent with animal studies demonstrating that hallucinogenic $5-\mathrm{HT}_{2 \mathrm{~A} / 2 \mathrm{C}}$ agonists such as DOI disrupt PPI in rats (Padich et al, 1996; Sipes and Geyer, 1994, 1995, 1997). One of these animal studies found that DOI reduced PPI across a wide range of ISIs from 25 to $180 \mathrm{~ms}$ (Canal et al, 2001) in contrast to the present ISI-dependent effects of psilocybin in humans. Unfortunately, there is as yet no published study that directly investigated the effect of psilocybin on PPI in animals.

A further important result is the finding that the psilocybin-induced attentional deficit as measured by the FAIR task correlated positively with the PPI reduction at the short $30 \mathrm{~ms}$ ISI but not with the PPI increases seen at longer ISIs. This finding supports the general concept that deficits in early pre-attentive information processing may underlie the more complex attentional and cognitive abnormalities in psychotic states such as schizophrenia (McGhie and Chapman, 1961; Nuechterlein and Dawson, 1984; Nuechterlein et al, 1994). Specifically, it is thought that schizophrenia patients suffer from a form of sensory inundation related to attentional deficits that are caused by a general inability to filter external intrusive stimuli and thereby focus on important and information-laden aspects of the environment (Braff et al, 1978, 2001; Nuechterlein and Dawson, 1984; Geyer and Braff, 1987). Along this line of argument, there is to date only one study that directly demonstrated that PPI deficits in schizophrenia subjects are correlated with distractibility in a continuous performance task and with lateralized attention on the Posner test (Karper et al, 1996). In addition, we recently found that unmedicated first-episode schizophrenia patients exhibit marked PPI deficits at 30 and $60 \mathrm{~ms}$ and a moderate PPI deficit at $120 \mathrm{~ms}$ prepulse intervals (Ludewig et al, 2003a, b). In one of our studies, schizophrenia patients with lower PPI capacity also showed lower attentional performance scores on the CANTAB rapid visual information processing (RVP) task than those with higher PPI levels (Ludewig et al, 2003b). Similarly, other studies found that PPI deficits in schizophrenia are correlated with thought disorder (Meincke et al, 2004; Perry and Braff, 1994; Perry et al, 1999). Furthermore, the finding of a positive correlation between PPI capacity and attentional performance in the present study is also of relevance to the view that a serotonergic dysfunction may contribute to the pathophysiology of cognitive deficits in schizophrenia (Meltzer and Nash, 1991; Roth et al, 2004). Although the role of the serotonergic system in the modulation of PPI is complex, there is accumulating evidence that atypical antipsychotics having higher affinity at $5-\mathrm{HT}_{2 \mathrm{~A}}$ than $\mathrm{D}_{2}$ receptors may be superior over typical antipsychotics in reversing PPI deficits (Kumari and Sharma, 2002) and partly also in ameliorating cognitive impairments in schizophrenia (Meltzer and Nash, 1991; Roth et al, 2004). Thus, the present findings further support the involvement of the serotonergic system in the modulation of sensorimotor gating and for the first time directly link PPI to controlled attentional performance. Indirectly, these findings are consistent with the suggested contributions of $5-\mathrm{HT}_{2 \mathrm{~A}}$ receptors to deficits in sensorimotor gating in schizophrenia patients.

The reason that psilocybin has dual ISI-dependent actions on PPI in humans while DOI disrupts PPI across ISIs in the rat is not known. The fact that psilocybin, in contrast to DOI, displays moderate agonistic activity at $5-\mathrm{HT}_{1 \mathrm{~A}}$ $\left(K_{\mathrm{i}}=190 \mathrm{nM}\right)$ receptors in addition to having strong agonistic action at $5-\mathrm{HT}_{2 \mathrm{~A}}$ receptors $\left(K_{\mathrm{i}}=6 \mathrm{nM}\right)$ (Aghajanian et al, 1972; Haigler and Aghajanian, 1974; Marek and Aghajanian, 1996; McKenna et al, 1990), raises the possibility that the dual effects of psilocybin on PPI in humans depend on some combination of $5-\mathrm{HT}_{2 \mathrm{~A}}$ or $5-\mathrm{HT}_{1 \mathrm{~A}}$ receptor stimulation, although downstream effects upon the glutamate and dopamine systems may also be implicated (Vollenweider et al, 1999b; Aghajanian and Marek, 2000). Moreover, the mechanism by which psilocybin reduces PPI at short and increases PPI at longer ISIs cannot be derived from the present study, but the currently available data on the effects of hallucinogens in animals and humans allow several possible explanations. First, in accordance with the finding that the disruption of PPI after application of DOI in the ventral pallidum or the nucleus accumbens in the rat was blocked by highly selective $5-\mathrm{HT}_{2 \mathrm{~A}}$ antagonists (Sipes and Geyer, 1997), it is possible that the psilocybin-induced PPI deficits at the $30 \mathrm{~ms}$ ISI in this study may primarily depend on $5-\mathrm{HT}_{2 \mathrm{~A}}$ receptor stimulation located in more basic modulatory structures of the startle circuit such as the striatum and thalamus, while the increases seen at longer ISIs may be due to a concomitant stimulation of $5-\mathrm{HT}_{1 \mathrm{~A}}$ receptors located in cortical neurons. In support of this interpretation, immunohistochemical studies demonstrate that $5-\mathrm{HT}_{1 \mathrm{~A}}$ receptors are co-localized with $5-\mathrm{HT}_{2 \mathrm{~A}}$ receptors in cortical pyramidal cells (Martin-Ruiz et al, 
2001), where both receptor subtypes display opposing effects when they were stimulated (Araneda and Andrade, 1991). It is also of note that the partial 5-HT $\mathrm{HA}_{1 \mathrm{~A}}$ agonist buspirone increased PPI in rats (Johansson et al, 1995), despite the many reports that more specific and full $5-\mathrm{HT}_{1 \mathrm{~A}}$ agonists disrupt PPI in rats (for review see Geyer et al (2001)). Thus, it might be possible that psilocybin, particularly with increasing doses, leads to an additional stimulation of $5-\mathrm{HT}_{1 \mathrm{~A}}$ receptors which in turn may have masked (at $60 \mathrm{~ms}$ ) or counteracted (at 120-240 ms) potential $5-\mathrm{HT}_{2 \mathrm{~A}}$ receptor-mediated PPI deficits at longer ISIs.

Second, it might also be possible that species-specific effects of serotonergic agonists on PPI, perhaps due to differences in transducing mechanisms, may contribute to the disparity between the human and animal findings. In fact, it was found that a variety of $5-\mathrm{HT}_{1 \mathrm{~A}}$ agonists dosedependently disrupt PPI in rats (for review see Geyer et al, 2001) but a diametrically opposite effect has been observed in mice (for review see Geyer et al, 2002). Moreover, we previously reported that the 5-HT releasing agent MDMAwhich indirectly stimulates both $5-\mathrm{HT}_{2 \mathrm{~A}}$ and $5-\mathrm{HT}_{1 \mathrm{~A}}$ receptors - also increases PPI at long $(120 \mathrm{~ms})$ but not short ISI $(30 \mathrm{~ms})$ in healthy human volunteers and disrupts PPI in rats (Vollenweider et al, 1999a).

Third, we cannot fully exclude the possibility that the psilocybin-induced PPI deficits at the short ISI seen in this study may depend on $5-\mathrm{HT}_{1 \mathrm{~A}}$ receptor stimulation, as both 5- $\mathrm{HT}_{1 \mathrm{~A}}$ and $5-\mathrm{HT}_{2 \mathrm{~A}}$ agonists disrupt PPI at least in the rat (reviewed by Geyer et al, 2001). However, the fact that administration of even relative low doses of $5-\mathrm{HT}_{1 \mathrm{~A}}$ agonist increased startle reactivity in the rat, which was not the case in this study with psilocybin in humans, may not favor such an interpretation.

Thus, in the absence of mechanistic studies, no firm conclusions can be drawn regarding the mediation of the observed ISI-dependent effects of psilocybin on PPI in humans. Hence, considerably more research is needed to clarify the mechanisms and sites of action of psilocybin on PPI in humans. For example, it will be important to determine whether the psilocybin-induced increase in PPI observed in humans in the present study is prevented by pretreatment with $5-\mathrm{HT}_{1 \mathrm{~A}}$ antagonists, as would be expected if this effect is due to a drug-induced stimulation of $5-\mathrm{HT}_{1 \mathrm{~A}}$ receptors as the opposite effect appears to be in rats (Sipes and Geyer, 1995) and the similar effect appears to be in mice (Dulawa et al, 2000).

One final caveat is that the highest dose of psilocybin $(315 \mu \mathrm{g} / \mathrm{kg})$ used in this study might not have been high enough to induce a full-blown psychotic state that might have been associated with more unidirectional effects of psilocybin on PPI, such as is seen in schizophrenia. Analysis of the 5D-ASC subscales revealed that psilocybin produced mostly depersonalization and derealization associated mania-like symptoms (OB scores) but only moderate anxious ego-disintegration, thought disorder, and fear of losing control (AED scores). Only at the highest dose of psilocybin some subjects experienced brief and transient episodes of paranoid thinking, altered meaning of percepts, and misinterpretation of the experimental situation. Given that the present dose regimen was well tolerated by our subjects in this as well as in previous studies with psilocybin in healthy volunteers, the exploration of somewhat higher doses of psilocybin on PPI seems to be justified in a later stage of the investigation.

To our knowledge this is the first study simultaneously modeling deficits in PPI and sustained attention (and their association) as well as psychopathological symptoms via challenge of a hallucinogenic drug in healthy human volunteers. The present study revealed complexities regarding the role of the serotonergic system in the modulation of PPI in humans. It appears that overactivity at $5-\mathrm{HT}_{2 \mathrm{~A}}$ receptors may be a common denominator of psilocybinand DOI-induced PPI deficits seen at short ISIs in human and animal models of schizophrenia. Furthermore, we suggest that the agonistic properties of psilocybin at 5- $\mathrm{HT}_{1 \mathrm{~A}}$ and/or $5-\mathrm{HT}_{2 \mathrm{~A}}$ receptors are responsible for the apparent disparity between the PPI-enhancing effects of psilocybin in humans and the PPI-disruptive effects of DOI in animals at long ISIs. The ISI-dependent effects of psilocybin on PPI stress the importance that startle sequences with graded ISIs (ranging from pre-attentive to perceivable ISIs) are used when pharmacological manipulations on PPI between rodents and humans are compared. Finally, further studies of the concomitant effects of psilocybin on PPI and attention may help to elucidate the roles and interdependencies of serotonin receptors and their hypothesized interactions with other neurotransmitter systems in schizophrenia.

\section{ACKNOWLEDGEMENTS}

We thank Dr Felix Hasler for technical support. This investigation was financially supported by the Heffter Research Institute, Santa Fe, New Mexico, USA, the Swiss Federal Office for Public health (BAG Grant No. 00.001023), and by a NARSAD Young Investigator Award given to $\mathrm{FH}$. Furthermore, Dr Boris B Quednow was supported by the Deutsche Forschungsgemeinschaft (DFG, Grant QU 218/ 1-1). Dr Mark A Geyer was supported by the US Veterans Affairs VISN 22 Mental Illness Research, Education, and Clinical Center and holds an equity interest in San Diego Instruments.

\section{REFERENCES}

Aghajanian GK, Haigler HJ, Bloom FE (1972). Lysergic acid diethylamide and serotonin: direct action on serotonin-containing neurons in rat brain. Life Sci 11: 615-622.

Aghajanian GK, Marek GJ (2000). Serotonin model of schizophrenia: emerging role of glutamate mechanisms. Brain Res Rev 31: 302-312.

Araneda R, Andrade R (1991). 5-Hydroxytryptamine2 and 5hydroxytryptamine $1 \mathrm{~A}$ receptors mediate opposing responses on membrane excitability in rat association cortex. Neuroscience 40: 399-412.

Braff DL, Geyer MA, Swerdlow NR (2001). Human studies of prepulse inhibition of startle: normal subjects, patient groups, and pharmacological studies. Psychopharmacology (Berlin) 156: 234-258.

Braff DL, Grillon C, Geyer MA (1992). Gating and habituation of the startle reflex in schizophrenic patients. Arch Gen Psychiatry 49: 206-215.

Braff DL, Stone C, Callaway E, Geyer MA, Glick I, Bali L (1978). Prestimulus effects on human startle reflex in normals and schizophrenics. Psychophysiol 15: 339-343. 
Cadenhead KS, Geyer MA, Braff DL (1993). Impaired startle prepulse inhibition and habituation in patients with schizotypal personality disorder. Am J Psychiatry 150: 1862-1869.

Cadenhead KS, Light GA, Geyer MA, Braff DL (2000). Sensory gating deficits assessed by the P50 event-related potential in subjects with schizotypal personality disorder. Am J Psychiatry 157: 55-59.

Canal NM, Gourevitch R, Sandner G (2001). Non-monotonic dependency of PPI on temporal parameters: differential alteration by ketamine and MK-801 as opposed to apomorphine and DOI. Psychopharmacology 156: 169-176.

Davis M, Walters JK (1977). Psilocybin: biphasic dose-response effects on the acoustic startle reflex in the rat. Pharmacol Biochem Behav 6: 427-431.

Derogatis LR, Lipman RS, Covi L (1976). SCL-90 (SymptomCheck-List): Self-report symptom inventory. In: Guy W (ed). ECDEU Assessement Manual for Psychopharmacology. NIMH: Rockville/Maryland.

Dittrich A (1994). Psychological aspects of altered states of consciousness of the LSD type: measurements of their basic dimensions and prediction of individual differences. In: Pletscher A, Ladewig D (eds). 50 Years of LSD. Current Status and Perspectives of Hallucinogens. Parthenon Publishing: New York. pp 101-118.

Dittrich A (1998). The standardized psychometric assessment of altered states of consciousness (ASCs) in humans. Pharmacopsychiat 31: 80-84.

Dittrich A, von Arx S, Staub S (1985). International study on altered states of consciousness (ISASC). Summary of the results. Germ J Psych 9: 319-339.

Dulawa SC, Scearce-Levie KA, Hen R, Geyer MA (2000). Serotonin releasers increase prepulse inhibition in serotonin 1B knockout mice. Psychopharmacology 149: 306-312.

Fahrenberg J, Hampel R, Selg H (1984). Das Freiburger Persönlichkeitsinventar FPI. Hogrefe: Göttingen.

Geyer MA (1998). Behavioral studies of hallucinogenic drugs in animals: implications for schizophrenia research. Pharmacopsychiatry 31: 73-79.

Geyer MA, Braff DL (1987). Startle habituation and sensorimotor gating in schizophrenia and related animal models. Schizophr Bull 13: 643-668.

Geyer MA, Krebs-Thomson K, Braff DL, Swerdlow NR (2001). Pharmacological studies of prepulse inhibition models of sensorimotor gating deficits in schizophrenia: a decade in review. Psychopharmacology (Berlin) 156: 117-154.

Geyer MA, McIlwain KL, Paylor R (2002). Mouse genetic models for prepulse inhibition: an early review. Mol Psychiatry 7: 10391053.

Geyer MA, Swerdlow NR, Mansbach RS, Braff DL (1990). Startle response models of sensorimotor gating and habituation deficits in schizophrenia. Brain Res Bull 25: 485-498.

Gouzoulis-Mayfrank E, Habermeyer E, Hermle L, Steinmeyer AM, Kunert HJ, Sass H (1998a). Hallucinogenic drug induced states resemble acute endogenous psychoses: results of an empirical study. Eur Psychiatry 13: 399-406.

Gouzoulis-Mayfrank E, Heekeren K, Thelen B, Lindenblatt H, Kovar KA, Sass H et al (1998b). Effects of the hallucinogen psilocybin on habituation and prepulse inhibition of the startle reflex in humans. Behav Pharmacol 9: 561-566.

Graham FK (1975). The more or less startling effects of weak prestimuli. Psychophysiology 12: 238-248.

Haigler HJ, Aghajanian GK (1974). Lysergic acid diethylamide and serotonin: a comparison of effects on serotonergic neurons and neurons receiving a serotonergic input. J Pharmac Exp Ther 188: 688-699.

Hasler F, Grimberg U, Benz MA, Huber T, Vollenweider FX (2004). Acute psychological and physiological effects of psilocybin in healthy humans: a double-blind, placebo-controlled dose-effect study. Psychopharmacology 172: 145-156.

Johansson C, Jackson DM, Zhang J, Svensson L (1995). Prepulse inhibition of acoustic startle, a measure of sensorimotor gating: effects of antipsychotics and other agents in rats. Pharmacol Biochem Behav 52: 649-654.

Karper LP, Freeman GK, Grillon C, Morgan CA, Charney DS, Krystal JH (1996). Preliminary evidence of an association between sensorimotor gating and distractibility in psychosis. J Neuropsychiatry Clin Neurosci 8: 60-66.

Kumari V, Sharma T (2002). Effects of typical and atypical antipsychotics on prepulse inhibition in schizophrenia: a critical evaluation of current evidence and directions for future research. Psychopharmacology 162: 97-101.

Kumari V, Soni W, Mathew VM, Sharma T (2000). Prepulse inhibition of the startle response in men with schizophrenia: effects of age of onset of illness, symptoms, and medication. Arch Gen Psychiatry 57: 609-614.

Ludewig K, Geyer MA, Vollenweider FX (2003a). Deficits in prepulse inhibition and habituation in never-medicated, firstepisode Schizophrenia. Biol Psychiatry 54: 121-128.

Ludewig K, Geyer MA, Vollenweider FX (2003b). Prepulse inhibition and habituation in first-episode schizophrenia. Biol Psychiatry 53: 118S.

Marek GJ, Aghajanian GK (1996). LSD and the phenethylamine hallucinogen DOI are potent partial agonists at 5-HT2A receptors on interneurons in rat piriform cortex. J Pharmac Exp Ther 278: 1373-1382.

Martin-Ruiz R, Puig MV, Celada P, Shapiro DA, Roth BL, Mengod $G$ et al (2001). Control of serotonergic function in medial prefrontal cortex by serotonin-2A receptors through a glutamate-dependent mechanism. J Neurosci 21: 9856-9866.

McGhie A, Chapman J (1961). Disorders of attention and perception in early schizophrenia. Br J Med Psychol 34: 103-116.

McKenna DJ, Repke DB, Peroutka SJ (1990). Differential interactions of indolealkylamines with 5-hydroxytrypamine receptor subtypes. Neuropharmacology 29: 193-198.

Meincke U, Mörth D, Voss T, Thelen B, Geyer MA, GouzoulisMayfrank E (2004). Prepulse inhibition of the acoustically evoked startle reflex in patients with an acute schizophrenic psychosis - a longitudinal study. Eur Arch Psychiatry Clin Neuosci 254: 415-421.

Meltzer HY, Nash JF (1991). Effects of antipsychotic drugs on serotonin receptors. Pharmacol Rev 43: 587-604.

Moosbrugger H, Oehlschlägel J (1996). FAIR. Frankfurter Aufmerksamkeitsinventar. Testmanual. Huber: Bern.

Neubauer AC, Knorr E (2006). Three paper-and-pencil tests for speed of information processing: Psychometric properties and correlations with intelligence. Intelligence 126: 123-151.

Nuechterlein KH, Dawson ME (1984). Information processing and attentional functioning in the developmental course of schizophrenic disorders. Schizophr Bull 10: 160-203.

Nuechterlein KH, Dawson ME, Green MF (1994). Informationprocessing abnormalities as neuropsychological vulnerability indicators for schizophrenia. Acta Psychiatr Scand 384(Suppl): 71-79.

Padich RA, McCloskey TC, Kehne JH (1996). 5-HT modulation of auditory and visual sensorimotor gating: II. Effects of the 5HT2A antagonist MDL 100907 on disruption of sound and light prepulse inhibition produced by 5-HT agonists in Wistar rats. Psychopharmacology (Berlin) 124: 107-116.

Parwani A, Duncan EJ, Bartlett E, Madonick SH, Efferen TR, Rajan $\mathrm{R}$ et al (2000). Impaired prepulse inhibition of acoustic startle in schizophrenia. Biol Psychiatry 47: 662-669.

Perry W, Braff DL (1994). Information-processing deficits and thought disorder in schizophrenia. Am J Psychiatry 151: 363-367. 
Perry W, Geyer MA, Braff DL (1999). Sensomotor gating and thought disturbance measured in close temporal proximity in schizophrenic patients. Arch Gen Psychiatry 56: 227-281.

Perry W, Minassian A, Feifel D, Braff DL (2001). Sensorimotor gating deficits in bipolar disorder patients with acute psychotic mania. Biol Psychiatry 50: 418-424.

Quednow BB, Wagner M, Westheide J, Beckmann K, Bliesener N, Maier W et al (2006). Sensorimotor gating and habituation of the startle response in schizophrenic patients randomly treated with amisulpride or olanzapine. Biol Psychiatry 59: 536-545.

Riba J, Rodriguez-Fornells A, Barbanoj MJ (2002). Effects of ayahuasca on sensory and sensorimotor gating in humans as measured by P50 suppression and prepulse inhibition of the startle reflex, respectively. Psychopharmacology (Berlin) 165: $18-28$.

Roth BL, Hanizavareh SM, Blum AE (2004). Serotonin receptors represent highly favorable molecular targets for cognitive enhancement in schizophrenia and other disorders. Psychopharmacology 174: 17-24.

Schell AM, Wynn JK, Dawson ME, Sinaii N, Niebala CB (2000). Automatic and controlled attentional processes in startle eyeblink modification: effects of habituation of the prepulse. Psychophysiology 37: 409-417.

Sipes TE, Geyer MA (1994). Multiple serotonin receptor subtypes modulate prepulse inhibition of the startle response in rats. Neuropharmacology 33: 441-448.

Sipes TE, Geyer MA (1995). DOI disruption of prepulse inhibition of startle in the rat is mediated by $5-\mathrm{HT} 2 \mathrm{~A}$ and not by $5-\mathrm{HT} 2 \mathrm{C}$ receptors. Behav Pharmacol 6: 839-842.

Sipes TE, Geyer MA (1997). DOI disrupts prepulse inhibition of startle in rats via 5-HT2A receptors in the ventral pallidum. Brain Res 761: 97-104.

Spielberger CD, Gorsuch RL, Lusheme RE (1970). STAI, Manual for the State-Trait-Anxiety-Inventory. Consulting Psychologists Press: Palo Alto.

StatSoft Inc. (2005). STATISTICA (data analysis software system), version 7.1 www.statsoft.com. Tulsa, OK.

Swerdlow NR, Braff DL, Geyer MA (2000). Animal models of deficient sensorimotor gating: what we know, what we think we know, and what we hope to know soon. Behav Pharmacol 11: 185-204.
Swerdlow NR, Braff DL, Taaid N, Geyer MA (1994). Assessing the validity of an animal model of deficient sensorimotor gating in schizophrenic patients. Arch Gen Psychiatry 51: 139-154.

Swerdlow NR, Geyer MA (1998). Using an animal model of deficient sensorimotor gating to study the pathophysiology and new treatments of schizophrenia. Schizophr Bull 24: 285-301.

Swerdlow NR, Geyer MA, Braff DL (2001). Neural circuit regulation of prepulse inhibition of startle in the rat: current knowledge and future challenges. Psychopharmacology (Berlin) 156: 194-215.

Swerdlow NR, Hartman PL, Auerbach PP (1996). Changes in sensorimotor inhibition across the menstrual cycle: implications for neuropsychiatric disorders. Biol Psychiatry 41: 452-460.

Vollenweider FX (1998). Advances and pathophysiological models of hallucinogen drug actions in humans: a preamble to schizophrenia research. Pharmacopsychiatry 31: 92-103.

Vollenweider FX (2001). Brain mechanisms of hallucinogens and entactogens. Dialog Clin Neurosci 3: 265-279.

Vollenweider FX, Gamma A, Liechti ME, Huber T (1998). Psychological and cardiovascular effects and short-term sequelae of MDMA ('Ecstasy') on MDMA-naive healthy volunteers. Neuropsychopharmacology 19: 241-251.

Vollenweider FX, Geyer MA (2001). A systems model of altered consciousness: Integrating natural and drug-induced psychoses. Brain Res Bull 56: 495-507.

Vollenweider FX, Leenders KL, Scharfetter C, Maguire P, Stadelmann O, Angst J (1997). Positron emission tomography and fluorodeoxyglucose studies of metabolic hyperfrontality and psychopathology in the psilocybin model of psychosis. Neuropsychopharmacology 16: 357-372.

Vollenweider FX, Remensberger S, Hell D, Geyer MA (1999a). Opposite effects of 3,4-methylenedioxymethamphetamine (MDMA) on sensorimotor gating in rats versus healthy humans. Psychopharmacology 143: 365-372.

Vollenweider FX, Vontobel P, Hell D, Leenders KL (1999b). 5-HT modulation of dopamine release in basal ganglia in psilocybininduced psychosis in man: A PET study with [11C]raclopride. Neuropsychopharmacology 20: 424-433.

Wittchen HU, Pfister H (1997). DIA-X-Interview. Swets Test Services: Frankfurt. 